DOI: $10.12731 / 2077-1770-2021-13-3-307-330$

УДК 811.112.2; 316.776.3+81'42

\title{
ВЕРБАЛЬНЫЕ СПОСОБЫ ПРЕОДОЛЕНИЯ КОММУНИКАТИВНЫХ НЕУДАЧ В ИНТЕРВЬЮ-ПОРТРЕТЕ (НА МАТЕРИАЛЕ НЕМЕЦКОЙ ПРЕССЫ)
}

\section{Ионкина Е.Ю., Тихаева В.В.,} Бганцева И.В., Тисленкова И.А.

Статья посвящена коммуникативно-прагматическому анализу речевого поведения участников диалогчческого взаимодействия в ситуациях возникновения коммуникативных неудач в немецких портретных интервью.

Цель исследования состоит в структурно-семантическом анализе диалогических последовательностей, содержаших коммуникативные неудачи, для выявления вербальных способов их устранения, репрезентированных в конкретных коммуникативных тактиках, использование которых необходимо для успешного протекания диалога-интервью.

Материалы и методы. Материалом для исследования послужсили тексты 120 портретных интервью, опубликованные в современных немецких интернет-изданиях. В ходе исследования были использованы контекстуальный и прагматический анализ в сочетании с методом структурного анализа элементов диалогической последовательности с коммуникативной неудачей.

Результаты. Проведенное исследование текстов немецких портретных интервью позволило выделить четыре тактики, которые имеют определенные способы вербального выражения и оказываются наиболее эффективныли для преодоления коммуникативных неудач. Бьло установлено, что диалогические последовательности с коммуникативной неудачей различаются по структуре и могут быль прямого/обратного/полного/комбинированного типа, посколь- 
ку коммуникативные неудачи возникают и устраняются не только в перспективе журналиста, но и собеседника. Выбор соответствующей тактики определяется степенью непонимания, спецификой возникшей коммуникативной неудачи, а также прагматическими параметрами ситуации диалога-интервью.

Область применения результатов. Полученные результаты могут найти практическое применение в специальных курсах по прагматике и психолингвистике, межкультурной коммуникации, а также журналистике.

Ключевые слова: коммуникативная неудача; коммуникативная тактика; вербальный способ; базовая диалогическая последовательность; интервью-портрет; журналист; собеседник

\section{VERBAL WAYS OF OVERCOMING COMMUNICATIVE FAILURES IN A PORTRAIT INTERVIEW (BASED ON THE GERMAN PRESS)}

\section{Ionkina E.Yu., Tikhaeva V.V., Bgantseva I.V., Tislenkova I.A.}

The article is devoted to the communicative and pragmatic analysis of the speech behavior of participants in dialogical interaction in situations of communicative failures in German portrait interviews.

Purpose. The article deals with a structural and semantic analysis of dialogical sequences containing communicative failures to identify verbal ways to eliminate them. The verbal ways are represented in specific communicative tactics, the use of which is necessary for the successful dialogue-interview.

Materials and methods. The texts of 120 portrait interviews published in modern German online publications were studied. In the course of the investigation, contextual and pragmatic analysis was used in combination with the structural analysis method of dialogical sequence elements with communicative failures.

Results. The study of the texts of the German portrait interviews allowed us to determine the most effective verbal ways to overcome com- 
municative failures and to identify four communicative tactics: explanations, paraphrasing, clarification and insistence. It was found that dialogical sequences with communicative failures differ in the structure and can be of a direct/reverse/complete/combined type, since communicative failures appear and are eliminated not only in the perspective of the journalist, but also of the interlocutor. The choice of appropriate tactics is determined by the degree of misunderstanding, the specifics of the communicative failure that has arisen, as well as by the pragmatic parameters of the dialogue-interview situation.

Practical implications. The results of the research can be used in special courses on pragmatics and psycholinguistics, intercultural communication and journalism.

Keywords: communicative failure; communicative tactics; verbal way; basic dialogical sequence; interview-portrait; journalist; interlocutor

\section{Введение}

Эффективное речевое воздействие - это такое, которое позволяет говорящему достичь поставленной цели и сохранить баланс отношений с собеседником (коммуникативное равновесие), то есть остаться с ним в нормальных отношениях, не поссориться [15, с. 62]. Успешное взаимодействие между участниками диалогического общения, в том числе и в интервью, напрямую зависит от коммуникативного комфорта, предполагающего благожелательный настрой собеседников, положительный тон общения. По мнению М.Л. Курьян, «создание коммуникативного комфорта выступает существенным средством оптимизации процесса межличностной коммуникации и связано с завоеванием расположения собеседника, умением ему понравиться, сохранением его «лица» при защите собственного» [9, с. 7]. В свою очередь, неуспешность, неэффективность речевого общения приводит к явлениям, которые в лингвистической литературе получают различные наименования: «коммуникативный дискомфорт» [12], «речевой конфликт» [16, с. 9], «коммуникативный сбой» [13, с. 216], «коммуникативная неудача» [10, с. 366-367]. Коммуникативная неудача является результатом 
неуспешной коммуникации, в основе которой лежат неправильно выбранные языковые средства или тактики и стратегии говорящего, отрицательное действие которых можно проследить на стадии коммуникативного дискомфорта $[1$, с. 6$]$.

Исследование медиадискурса в коммуникативно-прагматическом аспекте его успешности/неуспешности предпринималось в работах И.К. Айтеновой, Л.А. Балобановой (2016), Ю.С. Лавренчеко (2013), И.П. Смирновой (2010), П.Н. Босого (2006), Н.В. Муравьевой Н.В. (2002). Выявление так называемых уязвимых коммуникативных ситуаций или «зон риска» [17] для предупреждения коммуникативных неудач наряду со способами их преодоления [11; 18] становится все более актуальным в последние десятилетия. Однако на сегодняшний день анализ речевого поведения коммуникантов ограничивается рассмотрением речевых стратегий и тактик на протяжении всего интервью, тогда как особенности их речевого поведения в случае возникновения ситуации коммуникативной неудачи не попадают в поле зрения исследователей.

Актуальность настоящего исследования обусловлена недостаточной изученностью проблемы удачного/неудачного коммуникативного взаимодействия в интервью как публицистическом типе медиадискурса, а также отсутствием специальных исследований, посвященных способам преодоления коммуникативных неудач в интервью-портрете.

Цель исследования - выделить основные коммуникативные тактики участников диалогического взаимодействия, направленные на преодоление возникших коммуникативных неудач и восстановление взаимопонимания в интервью-портрете.

Поставленная цель предполагает решение следующих задач:

1) выявить диалогические последовательности интервью, содержащие коммуникативные неудачи и определить их структурный тип;

2) исследовать реплики коммуникантов, устраняющие коммуникативные неудачи, и выделить вербальные способы их преодоления;

3) определить факторы, обусловливающие использование тех или иных тактик в интервью-портрете. 
Объектом данного исследования выступают фрагменты немецких портретных интервью, в которых содержатся ситуации коммуникативных неудач. Предметом исследования являются корректирующие реплики коммуникантов на проблемном участке интервью.

\section{Материалы и методы исследования}

В качестве материала исследования были выбраны тексты портретных интервью, размещенные в открытом доступе в современных немецких интернет-изданиях: Spiegel Online, Focus Online, Neue Osnabrücker Zeitung (NOZ), Berliner Zeitung, Playboy. Было проанализировано около 120 интервью, героями которых выступают известные личности, имеющие достижения в различных профессиональных сферах (спортсмены, писатели, телеведущие, актеры, режиссеры, художники и т.д.), «просто» интересные люди и «звезды».

В соответствии с поставленной целью исследование проводилось с помощью методов контекстуального и прагматического анализа в сочетании с общенаучными методами наблюдения, описания и интерпретации языкового материала. Для выделения из текстов интервью диалогических последовательностей, содержащих коммуникативные неудачи, и их последующего описания был использован метод структурного анализа элементов последовательности, предложенный Л. Голетиани. Трем структурным элементам в базовой последовательности с КН соответствуют три реплики собеседников, выполняющие соответствующие функции: инициальная реплика, содержащая источник КН (реплика-источник или РИ), реплика, имплицитно или эксплицитно выявляющая произошедшую или возможную КН (реплика-выявление или РВ) и реплика, устраняющая КН (реплика-устранение или РУ) [3, с. 73].

\section{Результаты и обсуждение}

Коммуникативные неудачи, причины их возникновения, а также типология были изучены в работах многих отечественных лингвистов: Б.Ю. Городецкого, О.П. Ермаковой, Е.А. Земской, А. А. Романова, И.Г. Сабуровой, Н.К. Къневой, Т.В. Шмелевой; И.М. Кобозе- 
вой, Н.И. Формановской. Существующие определения, отличаясь в более или менее важных деталях, сходятся в одном: ориентация на взаимное понимание - это основное требование к каждому акту общения [5, с. 98]. В противопоставление этому требованию «полное или частичное непонимание высказывания партнёром коммуникации, т.е. неосуществление или неполное осуществление коммуникативного намерения говорящего» [6, с. 31], а также случаи, когда «определенные речевые произведения не выполняют своего функционального предназначения» [4, с. 67] становятся основанием для возникновения коммуникативных неудач. Несмотря на различие подходов к исследованию данного явления, большинство ученых вкладывают в определение понятия «коммуникативная неудача» ключевой компонент: нарушение взаимопонимания между партнерами по коммуникации, обусловленное непониманием конкретного речевого акта. Речь здесь идет, прежде всего, о понимании пропозиционального содержания высказывания, тогда как «непропозициональное понимание не может считаться коммуникативной неудачей в строгом смысле слова, потому что объектом понимания здесь является не сам РА, то есть не сама речь, а то, что вызывает эту речь и отображается в речи латентно» [20, с. 39]. Внутренние мотивы говорящего остаются скрытыми и не всегда могут быть однозначно поняты адресатом. Однако, понимание коммуникативного намерения говорящего, отражаемого в речевом акте, и самой коммуникативной ситуации, соотносимые с непропозициональным пониманием в коммуникативном акте, являются существенным условием удачной коммуникации. Применительно к диалогическому дискурсу, тот эффект, который производит высказывание говорящего на слушающего, играет основную роль в определении высказывания как удачного или неудачного.

Под «коммуникативной неудачей» (далее КН) в портретном интервью мы будем понимать возникшее в условиях конкретной интеракиии коммуникантов массмедийного дискурса несовпадение коммуникативных намерений говорящего и их прочтения слушающуим, т.е. полное или частичное непонимание высказывания одним 
из участников коммуникации и/или возникающий при этом непредусмотренный эмоциональный эффект. Анализ КН в конкретных ситуациях диалога-интервью проводился в рамках коммуникативно-прагматического подхода, а за основную структурно-семантическую единицу принималась базовая диалогическая последовательность, которая включает три элемента: источник, выявление и устранение. Поскольку в интервью-портрете журналисту принадлежит главная роль организатора и координатора беседы, за основу анализа принимались такие диалогические последовательности, в которых реплика-источник и реплика-устранение КН принадлежат журналисту, тогда как реплика-выявление КН остается за адресатом. Тем не менее, в процессе речевого взаимодействия интервьюируемый занимает активную позицию, и его реплики также могут становиться источником непонимания и приводить к КН. В таких случаях три реплики диалогической последовательности с КН имеют противоположную принадлежность коммуникантам в интервью-портрете. Условно мы обозначили две последовательности следующим образом:

I. прямая (РИ(Ж) - РВ(С) - РУ(Ж));

II. обратная (РИ(С) - PB(Ж) - РУ(C)), где Ж - журналист, С собеседник.

На первом этапе предпринятого нами исследования, результаты которого более подробно изложены в предыдущей работе [7], были установлены те коммуникативные ходы журналиста, которые представляют наибольший риск возникновения КН при неправильной интерпретации коммуникативного намерения со стороны собеседника. К ним относятся, к примеру, следующие структурно-семантические типы высказываний: провокационный вопрос/утверждение; личный вопрос; вопрос с иронией; оченочное утверждение (одобрение/похвала/неодобрение/упрек) в сочетании с вопросом; комплимент; утверждение-ввод новой темь; утверждение-мнение других источников информации [7, с. 82]. Названные типы инициальных реплик (РИ) журналиста используются в большинстве проанализированных нами портретных интервью и являются 
потенциальным источником возникновения КН при определенных прагматических условиях.

При анализе коммуникативных ситуаций интервью-портрета, были выявлены конкретные типы реакций адресата, которые свидетельствуют о нарушении взаимопонимания между коммуникантами и о наличии КН на определенном отрезке интервью. В определенной степени они зависят от структурно-семантического типа исходной реплики интервьюера. Способы устранения возникших КН, в свою очередь, напрямую обусловлены степенью непонимания и спецификой КН и представлены определенным набором тактик речевого общения, используемых журналистом/собеседником для преодоления КН. Под тактикой в данной работе понимается «совокупность приемов ведения беседы и линия поведения на определенном этапе в рамках отдельного разговора, нацеленного на достижение желательного эффекта или предотвращения нежелательного результата» $[14$, с. 7]. В настоящем исследовании мы сосредоточим основное внимание именно на вербальных способах устранения КН, тогда как к невербальным можно отнести, например, следующие: совершенствование коммуникативной культуры; ориентация на слушающего в разговоре; корректирование своего речевого поведения при возникновении коммуникативной неудачи; развитие умения контролировать свои эмоции и др. Перейдем к более детальному рассмотрению коммуникативных тактик преодоления КН.

\section{Вербальные способы преодоления КН}

Как показывает проведенное исследование, КН носят локальный характер в портретном интервью, не нарушают процесс общения в целом, но создают некоторые помехи в коммуникативном взаимодействии, которые нейтрализуются по ходу интервью и не приводят к смене темы. КН в большинстве случаев обусловлены неадекватным выбором со стороны журналиста лексических единиц для обозначения определенного явления действительности, что приводит к неоднозначной денотативной соотнесенности. Неверная референция как лингвистический фактор, а также отсутствие об- 
щих фоновых знаний коммуникантов как экстралингвистический фактор становятся основным препятствием на пути к достижению эффективного диалогического взаимодействия.

Реплика-выявление непонимания соответствует таким реакциям адресата, как вопрос-удивление, вопрос-переспрос, корректировка вопроса, вопрос-уточнение причины, уклончивый ответ/ирония, несогласие в сочетании с аргументированным ответом, восклицание-удивление в сочетании с несогласием. При этом сам факт непонимания может быть вербализован лексически в ответной реплике-констатации непонимания, которая представляет собой косвенную оценку высказывания журналиста как непонятного: «Ich verstehe die Frage nicht». Основная функция этих реплик - индикация непонимания. Говорящий сигнализирует о своих трудностях в поиске правильной интерпретации. А акт оценки предполагает наличие у оценивающего определенной ясности в коммуникативной картине [3, с.70].

Полная базовая диалогическая последовательность с КН имеет трехчленную структуру, в которой реплика-устранение КН следует сразу же за репликой-выявлением КН. Такие последовательности могут быть как прямого, так и обратного типа. Было установлено, что для преодоления непонимания в интервью-портрете применяются четыре коммуникативных тактики:

1. Тактика разъяснения, которая предполагает использование развернутого семантического контекста высказывания, с включением в данный контекст дополнительной информации, требуемой для понимания (в том числе с привлечением мнения других источников информации).

Как считает С.Е. Бугрова, «основные источники непонимания находятся в культурологической, социальной и личностной плоскостях, т.е. связаны с личностью коммуникантов» [2, с. 15]. Возникшую при этом информационную недостаточность, успешно восполняет коммуникативная тактика разъяснения, что можно продемонстрировать следующим примером:

I. (1) Playboy: Haben Sie eine starke Mutter?

(2) Schweiger: Wieso? 
(3) Playboy: Wenn man Ihre Filme sieht, könnte man Sie für einen Frauenversteher halten.

(4) Schweiger: Ich bin kein Frauenversteher. Als Mann eine Frau zu verstehen ist genauso unmöglich, wie als Frau einen Mann zu verstehen. Deswegen haben wir doch die ganzen Probleme. Vielleicht können Sie einen Psychoanalytiker engagieren, der sagt: Aha, deswegen sind seine Filme so. Ich habe tatsächlich eine starke Mutter, aber ich habe nie unter ihr gelitten, ich liebe sie. Und ich will auch nicht Frauen verstehen, sondern einfach Filme machen, die ich mir selber angucken möchte [TL].

Представленный отрывок интервью с известным немецким кинорежиссером Т. Швайгером журналист начинает с вопроса о характере его матери, чем сразу вызывает непонимание у собеседника. Непонимание адресата вербализуется в его уточняющем вопросе (2): «Wieso?». Для преодоления возникшей КН журналист прибегает к тактике разъяснения (3), характеризуя своего собеседника как «знатока женщин» («Frauenversteher»), о чем можно судить по его фильмам. Хотя адресат и не соглашается с данной характеристикой, но признает, что его мать действительно имеет характер сильной женщины. Полученный развернутый ответ собеседника подтверждает успешность коммуникативного хода журналиста в преодолении возникшего непонимания.

2. Тактика перефразирования, которая служит для «содержательного перекодирования сообщения без изменения существа фактуальной информации» $[2$, c.17] и наиболее часто приобретает форму синонимической трансформации.

В отличие от тактики разъяснения, которая предполагает семантическую трансформацию всей реплики, тактика перефразирования используется чаще всего для пояснения одного содержательного элемента в структуре высказывания. Как показывает анализ интервью, данная тактика может активно применяться не только журналистом, но и собеседником, если его реплика становится источником КН и приводит к непониманию со стороны интервьюера. Это можно продемонстрировать следующим примером: 
II. (1) NOZ: Ihre künstlerische Laufbahn begann auf dem Internat der Wiener Sängerknaben. In welchem Alter?

(2) Karl: Dritte Klasse Grundschule, heißt das wohl in Deutschland. Ich bin also mit acht oder neun ins Internat gekommen und blieb dann bis zur Mutation.

(3) NOZ: Mutation?

(4) Karl: Bis zum Stimmbruch. In Österreich heißt das so. Man wird dann zum Mutanten und kann sich dann aussuchen, ob man im Mutantenheim die Schule abschließen oder wieder nach Hause will. $<\ldots>$.

(5) NOZ: Sind Sie eigentlich aus eigenem Antrieb zu den Sängerknaben gegangen?

(6) Karl: Meine Eltern hatten ein Restaurant und waren mit ihrer Arbeit beschäftigt. $<\ldots>$ [FK].

Данный отрывок интервью с австрийским актером Ф. Карлом является примером обратной базовой диалогической последовательности, в которой реплика-выявление КН принадлежит журналисту и вербализуется в форме вопроса-переспроса (3). Журналист интересуется, в каком возрасте собеседник начал свою карьеру в венском мужском хоре при интернате (1). Развернутый ответ адресата и употребление лексической единицы «Mutation» («мутация») (2) становится источником непонимания для интервьюера. Он оказывается незнаком со значением данного слова, ввиду культурно-обусловленного различия между австрийским и немецким пониманием данного явления. Адресат перефразирует непонятый элемент высказывания (4), используя синоним «Stimmbruch» («ломка голоса»), тем самым восстанавливая взаимопонимание на заданном отрезке интервью. Последующий вопрос журналиста (5) продолжает коммуникативное взаимодействие в рамках заданной темы.

3. Тактика уточнения реализуется через уточняющий вопрос, который применяется для конкретизации значения элемента в семантической структуре высказывания; а также через уточняющее высказывание, служащее корректировкой речевого выбора лексической единицы или языковой формы слова. 
Даже если сам говорящий обладает достаточной лингвистической и коммуникативной компетенцией, он может иметь ошибочные прагматические пресуппозиции относительно фонда знаний, интересов и коммуникативной компетенции адресата [19]. Именно различие пресуппозиций коммуникантов становится еще одной причиной смыслового непонимания адресатом вопроса или утверждения журналиста. Для устранения КН широко используется тактика уточнения, основными синтаксическими элементами которой наиболее часто являются вопрос-переспрос, уточняющий вопрос в сочетании с аргументацией или опровержением, а также корректировка отдельной лексической единицы. Рассмотрим два примера:

III. (1) Playboy: Das ist doch Ihre Spezialität - schwierige Schauplätze.

(2) Herzog: Nicht schwierige, glaubwürdige.

(3) Playboy: Ist L. A. ein glaubwürdiger Schauplatz für Ihr Leben?

(4) Herzog: Ich lebe zum großen Teil auf meinen Sets. Und ich wohne seit 17 Jahren in Los Angeles, weil ich meine Frau vor 17 Jahren kennengelernt habe und wir seitdem nie auseinander gewesen [WH].

IV. (1) Playboy: Haben Sie Angst davor, spießig zu werden?

(2) Campino: Was heißt schon spießig? Man hat eine Kleinfamilie und wohnt im Vorstadthäuschen, weil das Geld nur dafür reicht? Damit habe ich überhaupt kein Problem. Mit 50 Jahren schreie ich auch keine Parolen mehr heraus für Kids, die sich radikal von ihren Eltern abgrenzen wollen. Das bin ich nicht mehr. Denn allein durch mein Vatersein ist eine ganz andere Erdung da. Das Leben dreht sich nicht mehr nur um einen selbst. <.. >.

(3) Playboy: Verantwortung statt Anarchie?

(4) Campino: Mit dem Begriff Verantwortung konnte ich mit Ende 20 überhaupt nichts anfangen. Bei unseren Konzerten hieß es immer: Betreten auf eigene Gefahr! Wir übernehmen als Tote Hosen keinerlei Verantwortung. Das war aber ein Riesenirrtum. $<\ldots>$ [SC].

В примере (III) собеседник прибегает к тактике уточнения ввиду неудачного выбора лексической единицы в исходной реплике жур- 
налиста (1). В данном отрывке интервью с немецким режиссером В. Герцогом интервьюер полагает, что выбор сложных мест для съемки («schwierige Schauplätze») - это специфика работы режиссера. Собеседник не соглашается с такой формулировкой и корректирует реплику интервьюера (2), заменяя лексему «schwierig» («сложный») на «glaubwürdig» («правдоподобный»). Журналист принимает данную корректировку и задает следующий уточняющий вопрос (3).

В примере (IV), который представляет собой отрывок из интервью с немецким музыкантом Д. Кампино, к тактике уточнения снова прибегает сам адресат. Герой интервью проводит некоторые параллели своего сходства с отцом, отраженные в песне из его нового альбома («Draußen vor der Tür»). На основе этих воспоминаний журналист делает вывод о мещанском характере своего собеседника («spießig») и высказывает свои опасения в вопросе (1). Ответная реплика адресата содержит элемент частичного непонимания, что вербально выражается в конкретизирующем вопросе-удивлении («Was heißt schon spießig?») (2). Тем самым адресат выражает свое откровенное несогласие с постановкой вопроса журналистом и далее аргументирует свою точку зрения. Журналист делает свой вывод из сказанного, логически продолжая тему следующим вопросом (3).

Как видно из двух приведенных примеров, причина КН зачастую кроется в «неудачном структурировании информации» субъектом речи [8, с. 64]. Несоответствие между формулировкой высказывания журналиста и реальными знаниями адресата (пресуппозициями) приводит к необходимости корректировки и уточнения со стороны последнего. КН преодолевается самим адресатом уже в реплике-выявлении (2) и не требует устранения со стороны журналиста, который продолжает интервью новым вопросом в рамках обозначенной темы. Такие базовые диалогические последовательности можно считать неполными или комбинированными, состоящими только из двух структурных элементов: реплика-источник и реплика-выявление, устраняющая КН.

4. Тактика настаивания реализуется через повторный вопрос, на который ранее не последовал ответ адресата; через наводящий во- 
прос, содержащий предполагаемый вариант ответа; через прямую или косвенную просьбу дать ответ.

Тактика настаивания применяется в тех случаях, когда наблюдается явное несоответствие между коммуникативным намерением интервьюера и собеседника: журналист намеревается получить развернутый ответ, а собеседник не желает вдаваться в подробности, дает уклончивый или ироничный ответ. Самым распространенным способом повлиять на адресата, чтобы все-таки получить желаемую информацию является повторный вопрос, который задается с частичным изменением контекста. В данном случае речь идет о вариативном повторе, который понимается как «видоизменение контекста при его повторном употреблении» [11, с. 115]. Цель вариативного повтора - снять возможные трудности в понимании и «разговорить» собеседника. Помимо повторного вопроса тактика настаивания также реализуется через наводящий вопрос или косвенную просьбу дать ответ. Рассмотрим примеры:

V. (1) SPIEGEL ONLINE: Sie haben sich auf die Spur Ihrer Lieblingsmarken begeben, die Marken aber nicht genannt. Warum nicht?

(2) Müller-Hellmann: Das ist ein kniffliges Thema...

(3) SPIEGEL ONLINE: ...weil der Anwalt ihres Verlags davon abgeraten hat?

(4) Müller-Hellmann: Wir haben in der Tat darum gerungen, welche Namen wir rausnehmen und welche drinbleiben. Jetzt ist es ein Kompromiss: Die Namen der Kleidungsstücke und der Menschen sind drin, in zwei Kapiteln sind die Markennamen geblieben, aber die anderen Markennamen sind raus [IMH].

VI. (1) NOZ: Es gibt viele Frauen, die sich eigentlich nicht so sehr für Sport interessieren, aber einschalten, wenn Sie moderieren. Haben Sie was von Schwiegermutters Liebling?

(2) Bommes: Das hat ja einen Beigeschmack - als wenn Sie jetzt „Allzweckwaffe" zu mir sagen würden. Mit den beiden Begriffen musste sich Jörg Pilawa auch immer auseinandersetzen. Da hat man das Gefühl, man bekäme ein Stückchen Coolness und Männlichkeit abgesprochen.

(3) NOZ: Sind Sie nun Schwiegermutters Liebling, oder sind Sie es nicht? 
(4) Bommes: (lacht) Ich habe überhaupt kein Problem damit, wenn Frauen es gut finden, was ich im Fernsehen mache. Ganz im Gegenteil. Und wenn diese Frauen Schwiegermütter sind, ist es auch in Ordnung. $<\ldots>$.

(5) NOZ: Bei Ihrer eigenen Schwiegermutter dürften Sie auf jeden Fall einen Stein im Brett haben - Ihre Freundin Julia Westlake hat letzten Monat ihren zweiten Sohn zur Welt gebracht.

(6) Bommes: Das haben wir alles gut hinbekommen - ich glaube, damit ist sie ganz zufrieden $[\mathrm{AB}]$.

Пример (V) является отрывком из интервью с немецкой писательницей И. Мюллер-Хельманн на тему моды и производства текстиля в странах Азии, которую она описывает в своей новой книге. Журналист интересуется, почему героиня интервью не назвала в книге свои любимые фабричные марки вещей (1). Собеседник пытается уйти от ответа, ссылаясь на то, что это довольно «щекотливая» тема («еin kniffliges Thema») (2). Журналист, однако, желает знать конкретную причину и предлагает свое объяснение в наводящем вопросе (3). В последующей реплике (4) адресат игнорирует предположение журналиста, но дает аргументированный ответ на его первый вопрос.

Отрывок интервью (VI) с немецким ведущим спортивных телепрограмм А. Боммесом посвящен теме спорта и работе на телевидении. В первой реплике (1) журналист желает знать, характерно ли для героя интервью быть «любимчиком тещи» («Schwiegermutters Liebling»), обосновывая свой вопрос тем, что его собеседник пользуется популярностью на телевидении даже у женщин, не интересующихся спортом. Адресат не дает прямой ответ, а выражает лишь свое отношение к вопросу такого рода (2), полагая, что Ёрг Пилава лучше бы справился с этим понятием. Журналист не удовлетворен таким ответом и повторяет свой вопрос, формулируя его в альтернативной форме (3). Собеседник снова не дает прямой ответ, отшучивается, однако косвенно подтверждает, что, если среди его зрительской аудитории есть и тещи, то все в порядке (4). В последующей реплике журналист плавно переходит уже к теме «личной жизни» собеседника. 
Как видно из данных примеров, коммуникативное намерение журналиста реализуется не сразу, однако с помощью тактики настаивания он добивается желаемого ответа собеседника, преодолевая возникшее недопонимание.

\section{Заключение}

1. Проведенное исследование текстов немецких портретных интервью показало, что КН, обусловленные не(до)пониманием конкретного высказывания (его семантического и прагматического плана), могут обнаруживаться как в перспективе журналиста, так и в перспективе собеседника. Различия в фоновых знаниях, лингвистической и коммуникативной компетенции, а также психологические различия между говорящим и адресатом (например, его стремление уйти от ответа) являются основными причинами возникновения КН и становятся теми факторами, которые напрямую определяют выбор соответствующего вербального способа их устранения.

2. Диалогические последовательности с КН в интервью-портрете по своей структуре могут быть прямыми и обратными, а также полными и комбинированными, в зависимости от того, кому принадлежит ведущая роль в устранении возникшей КН - журналисту или собеседнику.

3. Для преодоления КН в интервью-портрете наиболее эффективными оказываются четыре коммуникативных тактики, представленные определенными вербальными способами своего выражения. Тактики разъяснения, перефразирования и уточнения активно используются не только журналистом, но и собеседником, поскольку смысловое непонимание может наблюдаться со стороны обоих участников диалогического общения. При использовании тактики настаивания приоритет всегда остается за журналистом. Способы преодоления КН помогают устранить непонимание на проблемном участке интервью, создавая лишь временное препятствие в развитии темы, и способствуют дальнейшему успешному коммуникативному взаимодействию его участников. 


\section{Список литературы}

1. Айтенова И.К., Балобанова Л.А. Речевое поведение радиоведущего в ситуациях коммуникативного дискомфорта (на примере программ информационно-развлекательного вещания) // Вестник Томского гос. ун-та. Филология. 2016. № 5 (43). С. 5-23. https://doi. org/10.17223/19986645/43/1

2. Бугрова С.Е. Коммуникативные неудачи и способы их преодоления в неофициальном англоязычном общении: Автореф. дис. ... канд. филол. наук. Нижний Новгород, 2013. 24 с.

3. Голетиани Л. Коммуникативная неудача в диалоге: на материале русского и украинского языков. Мюнхен: Otto Sagner Verlag, 2003. 412 с.

4. Городецкий Б.Ю., Кобозева, И.М., Сабурова, И.Г. К типологии коммуникативных неудач // Диалоговое взаимодействие и представление знаний: сб. ст. Новосибирск, 1985. С. 64-78.

5. Емельянова О.В. Коммуникативные неудачи при идентификации референта // Трехаспектность грамматики (на материале английского языка): сб. статей / отв. ред. В. В. Бурлаков. СПб: Изд-во СПбГУ, 1992. C. 97-114.

6. Ермакова О.Н., Земская Е.А. К построению типологии коммуникативных неудач (на материале естественного русского диалога) // Русский язык в его функционировании. Коммуникативно-прагматический аспект. М.: Наука, 1993. С. 30-64.

7. Ионкина Е.Ю., Тихаева В.В. Коммуникативные неудачи в интервью-портрете (на материале немецкого языка) // Вестник Челябинского государственного университета. Серия: Филологические науки. 2019. № 4 (426). Вып. 116. С. 80-89. https://doi. org/10.24411/1994-2796-2019-10411

8. Кукушкина О.В. Основные типы речевых неудач в русских письменных текстах. М.: Диалог - МГУ, 1998. 173 с.

9. Курьян М.Л. Средства оптимизации процесса межличностной коммуникации в англоязычном языковом пространстве: Автореф. дис. ... канд. филол. наук. Н. Новгород, 2006. 24 с.

10. Ларина Т.В. Коммуникативные неудачи в русско-английском диалоге // Конфликт в языке и коммуникации: сб. статей / сост. и отв. ред. Л.Л. Федорова. М.: РГГУ, 2011. С. 366-379. 
11. Маркова В.А. Вариативный повтор как средство преодоления коммуникативной неудачи в устной диалогической речи // Филологические науки. Вопросы теории и практики. Тамбов: Грамота, 2016. № 5(59): в 3-х ч. Ч. 3. С. 114-118.

12. Мартынова Е.М. Типология явлений коммуникативного дискомфорта в ситуациях диалога: Дис. ...канд. филол. наук. Орел, 2000. $229 \mathrm{c}$.

13. Мачина О.А. Коммуникативный сбой как следствие транспонирования прагматических типов предложения // Вестник Московского государственного лингвистического университета. 2010. Вып. 27. C. 216-226.

14. Плотникова О.А. Стратегии контроля диалогического взаимодействия в интервью: Автореф. дис. ... канд. филол. наук. Омск, 2007. $23 \mathrm{c}$.

15. Стернин И.А. Введение в речевое воздействие. Воронеж, 2001. 227 c.

16. Третьякова В.С. Речевой конфликт и гармонизация общения: Автореф. дис. ... д-ра филол. наук. М., 2003, 36 с.

17. Черняк В.Д. «Зоны риска» в лексиконе языковой личности: к основаниям коммуникативных неудач // Вестник Томского гос. пед. ун-та. Серия Гуманитарные науки (Филология). 2005. Вып. 3. С. 96-100.

18. Яшина Н.В. Коммуникативные неудачи в телеинтервью (на материале американского варианта английского языка) // Верхневолжский филологический вестник. 2017. №2. С. 66-70.

19. Humphreys-Jones C. The structure of misunderstandings // Communication Failure in Dialogue and Discourse. Amsterdam, New York, Oxford, 1987, pp. 25-33.

20. Wright G. H. Erklären und Verstehen. Frankfurt/M, 1991. 197 S.

\section{Источники}

$A B$ - Alexander Bommes im Interview [Электронный ресурс]. URL: https://www.noz.de/deutschland-welt/medien/artikel/1332/2206-wojo-08bommes\# gallery\&0\&0\&1332 (дата обращения: 10.06.2021). 
$F K$ - Fritz Karl im Interview [Электронный pecypc]. URL: http://www. noz.de/deutschland-und-welt/kultur/fernsehen/524193 38/fritz-karl-ueberseinen-speziellen-humor-wiener-saengerknaben-und-fliegenfischer (дата обращения: 28.06.2021).

IMH - Imke Müller-Hellmann im Interview [Электронный ресурс]. URL: http://www.spiegel.de/stil/ leute-machen-kleider-von-imke-mueller-hellmannfast-fashion-und-ihre-folgen-a-1182965.html (дата обращения: 10.06.2021).

$S C$ - Interview mit Sänger Campino [Электронный ресурc]. URL: http://www.focus.de/ kultur/ musik/tid-25970/interview-mit-saengercampino-ich-brauchte-die-exzesse-und-den-kontrollverlust_aid_759804. html (дата обращения: 15.05.2021).

$T L$ - Til Schweiger im Interview [Электронный pecypc]. URL: http:// www.focus.de/panorama/welt/ best-of-playboy/interview/tid-21168/tilschweiger-ich-wuerde-keinen-kindermoerder -spielen_aid_595359.html (дата обращения: 25.06.2021).

WH - Werner Herzog im Interview [Электронный ресурс]. URL: http://www.focus.de/panorama/ welt/best-of-playboy/interview/tid29154/werner-herzog-ich-bin-gut-wenn-es-unge muetliche-leute-brauchtes-ist-immer-einfach-mit-wirklich-professionellen-leuten-zu-arbeiten aid_903368.html (дата обращения: 25.06.2021).

\section{References}

1. Aitenova I.K., Balobanova L.A. Rechevoe povedenie radiovedushchego v situatsiyakh kommunikativnogo diskomforta (na primere program informatsionno-razvlekatelnogo veshchaniya) [Speech behavior of a radio host in situations of communicative discomfort (on the example of information and entertainment broadcasting programs)]. Vestnik Tomskogo gosudarstvennogo universiteta. Filologiya [Bulletin of the Tomsk State University. Philology], 2016, no. 5 (43), pp. 5-23. https:// doi.org/10.17223/19986645/43/1

2. Bugrova S.E. Kommunikativnye neudachi i sposoby ikh preodoleniya $v$ neofitsialnom angloyazychnom obshchenii [Communicative failures and ways to overcome them in informal English-speaking communication]. Abstract of PhD dissertation. Nizhniy Novgorod, 2013, 24 p. 
3. Goletiani L. Kommunikativnaya neudacha v dialoge: na materiale russkogo i ukrainskogo yazykov [Communicative failure in a dialogue: on the material of the Russian and Ukrainian languages]. Munich: Otto Sagner Publ., 2003, 412 p.

4. Gorodetskiy B.Y., Kobozeva I.M., Saburova I.G. K tipologii kommunikativnyh neudach [To the typology of communicative failures]. Dialogovoe vzaimodejstvie i predstavlenie znanij [Dialog interaction and knowledge representation]. Collection of articles, Novosibirsk, 1985, pp. 64-78.

5. Emelyanova O.V. Kommunikativnye neudachi pri identifikatsii referenta [Communicative failures in the identification of a referent]. Trejkhaspektost' grammatiki (na materiale anglijskogo yazyka) [Three-aspect ratio grammar (in the English language). Collection of articles, ed. by V.V. Burlakov. St. Petersburg: Publishing House of St. Petersburg State University, 1992, pp. 97-114.

6. Ermakova O.H., Zemskaya E.A. K postroeniyu tipologii kommunikativnykh neudach (na materiale estestvennogo russkogo dialoga) [To the construction of the typology of communicative failures (based on the material of the Natural Russian dialogue)]. Russkij yazyk v ego funktsionirovanii. Kommunikativno-pragmaticheskij aspekt) [Russian language in its functioning: Communicative and pragmatic aspect]. Moscow: Nauka, 1993, pp. 30-64.

7. Ionkina E.Yu., Tikhaeva V.V. Kommunikativnye neudachi v interv'yu-portrete (na materiale nemetskogo yazyka) [Communicative failures in a portrait interview (based on the material of the German language)]. Vestnik Chelyabinskogo gosudarstvennogo universiteta. Seriya: Filologicheskie nauki [Bulletin of the Chelyabinsk State University. Series: Philological sciences], 2019, no. 4 (426), pp. 80-89. https://doi. org/10.24411/1994-2796-2019-10411

8. Kukushkina O.V. Osnovnye tipy rechevyh neudach v russkih pis'mennyh tekstah [The main types of speech failures in Russian written texts]. Moscow: Dialog-MSU Publ., 1998, 173 p.

9. Kuryan M.L. Sredstva optimizatsii protsessa mezhlichnostnoj kommunikatsii v angloyazychnom yazykovom prostranstve [Means of optimiz- 
ing the process of interpersonal communication in the English-speaking language space]. Abstract of $\mathrm{PhD}$ dissertation. Nizhniy Novgorod, 2006, $24 \mathrm{p}$.

10. Larina T.V. Kommunikativnye neudachi v russko-anglijskom dialoge [Communicative failures in the Russian-English dialogue]. Konflikt $v$ yazyke $i$ kommunikatsii [Conflict in the language and communication]. Collection of articles, ed. by L.L. Fejdorov. Moscow, RSUH, 2011, pp. 366-379.

11. Markova V.A. Variativnyj povtor kak sredstvo preodoleniya kommunikativnoj neudachi v ustnoj dialogicheskoj rechi [Variative repetition as a means of overcoming communicative failure in oral dialogic speech]. Filologicheskie nauki. Voprosy teorii i praktiki. [Philological sciences. Questions of theory and practice]. Tambov: Gramota, 2016, no. 5 (59), pp. 114-118.

12. Martynova E.M. Tipologija yavlenij kommunikativnogo diskomforta v situatsiyakh dialoga [Typology of the phenomena of communicative discomfort in dialogue situations]. PhD dissertation. Orel, 2000, 229 p.

13. Machina O.A. Kommunikativnyj sboj kak sledstvie transponirovaniya pragmaticheskih tipov predlozheniya [Communicative failure as a consequence of the transposition of pragmatic types of sentences]. Vestnik Moskovskogo gosudarstvennogo lingvisticheskogo universiteta [Bulletin of the Moscow State Linguistic University], 2010, no. 27, pp. 216-226.

14. Plotnikova O.A. Strategii kontrolya dialogicheskogo vzaimodejstviya v intervjyu [Strategies for controlling dialogic interaction in an interview]. Abstract of PhD dissertation. Omsk, 2007, 23 p.

15. Sternin I.A. Vvedenie v rechevoe vozdejstvie [Introduction into the speech influence]. Voronezh: Voronezh Publ., 2001, 227 p.

16. Tretyakova V.S. Rechevoj konflikt i garmonizatsiya obshcheniya [Speech conflict and harmonization of communication]. Abstract of $\mathrm{PhD}$ dissertation. Moscow, 2003, $36 \mathrm{p}$.

17. Chernyak V.D. «Zony riska» v leksikone yazykovoj lichnosti: k osnovaniyam kommunikativnyh neudach ["Risk zones" in the lexicon of a linguistic personality: on the grounds of communicative failures]. Vestnik Tomskogo gosudarstvennogo pedagogicheskogo universiteta. 
Seriya: Gumanitarnye nauki (Filologiya) [Bulletin of the Tomsk State Pedagogical University. The Humanities (Philology) series], 2005, no. 3. pp. 96-100.

18. Yashina N.V. Kommunikativnye neudachi v teleintervjyu (na materiale amerikanskogo varianta anglijskogo yazyka) [Communicative failures in TV interviews (based on the material of the American version of the English language)]. Verkhnevolzhskij filologicheskij vestnik [Verkhnevolzhsk Philological Bulletin], 2017, no. 2, pp. 66-70.

19. Humphreys-Jones K. The structure of misunderstanding. In: G. Ronan (Ed.), Communicative failures in dialogue and discourse. Amsterdam, New York, Oxford, 1987, pp. 25-33.

20. Wright G.H. Erklären and Verstehen. Frankfurt/M., 1991, 197 S.

\section{Sources}

$A B$ - Alexander Bommes im Interview. URL: https://www.noz.de/ deutschland-welt/medien/artikel/1332/2206-wojo-08-bommes\#gallery\&0\&0\&1332 (accessed 10.06.2021). (In German).

$F K$ - Fritz Karl im Interview. URL: http://www.noz.de/deutschland-undwelt/kultur/fernsehen/524193 38/fritz-karl-ueber-seinen-speziellen-humor-wiener-saengerknaben-und-fliegenfischer (accessed 28.06.2021). (In German).

IMH - Imke Müller-Hellmann im Interview. URL: http://www.spiegel. de/stil/ leute-machen-kleider-von-imke-mueller-hellmann-fast-fashion-undihre-folgen-a-1182965.html (accessed 10.06.2021). (In German).

SC - Interview mit Sänger Campino. URL: http://www.focus.de/ kultur/ musik/tid-25970/interview-mit-saenger-campino-ich-brauchte-die-exzesse-und-den-kontrollverlust_aid_759804.html (accessed 15.05.2021). (In German).

$T L$ - Til Schweiger im Interview. URL: http://www.focus.de/panorama/ welt/ best-of-playboy/interview/tid-21168/til-schweiger-ich-wuerde-keinen-kindermoerder -spielen_aid_595359.html (accessed 25.06.2021). (In German).

WH - Werner Herzog im Interview. URL: http://www.focus.de/ panorama/ welt/best-of-playboy/interview/tid-29154/werner-herzogich-bin-gut-wenn-es-unge muetliche-leute-braucht-es-ist-immer-ein- 
fach-mit-wirklich-professionellen-leuten-zu-arbeiten_aid_903368.html (accessed 25.06.2021). (In German).

\section{ДАННЫЕ ОБ АВТОРАХ}

Ионкина Екатерина Юрьевна, кандидат филологических наук, доцент кафедры «Иностранные языки»

ФГБОУ ВО «Волгоградский государственный технический университет»

ул. проспект имени В.И. Ленина, 28, г. Волгоград, 400005, Российская Федераичи

katya_dzhandalie@mail.ru

Тихаева Виктория Викторовна, кандидат педагогических наук, доцент кафедры «Иностранные языки»

ФГБОУ ВО «Волгоградский государственный технический университет»

ул. проспект имени В.И. Ленина, 28, г. Волгоград, 400005,

Российская Федерачия

tilsitka@yandex.ru

Бганцева Ирина Владимировна, доктор педагогических наук, профессор кафедры «Иностранные языки» ФГБОУ ВО «Волгоградский государственный технический университет»

ул. проспект имени В.И. Ленина, 28, г. Волгоград, 400005, Российская Федерациия irina07085@rambler.ru

Тисленкова Ирина Александровна, кандидат филологических наук, доцент кафедры «Иностранные языки» ФГБОУ ВО «Волгоградский государственный технический университет»

ул. проспект имени В.И. Ленина, 28, г. Волгоград, 400005, Российская Федерачии tislenkova@bk.ru 


\section{DATA ABOUT THE ATHOURS}

Ekaterina Yu. Ionkina, Cand. Sci. (Philology), Associate Professor, Department of Foreign Languages

Volgograd State Technical University

28, prospekt imeni V.I. Lenina, Volgograd, 400005, Russian Federation

katya_dzhandalie@mail.ru

ORCID 0000-0001-5667-5881

Viktoria V. Tikhaeva, Cand. Sci. (Pedagogy), Associate Professor, Department of Foreign Languages

Volgograd State Technical University

28, prospekt imeni V.I. Lenina, Volgograd, 400005, Russian Federation

tilsitka@yandex.ru

ORCID: 0000-0002-3338-8422

Irina V. Bgantseva, Doc. Sci. (Pedagogy), Professor, Department of Foreign Languages

Volgograd State Technical University

28, prospekt imeni V.I. Lenina, Volgograd, 400005, Russian Federation

irina07085@rambler.ru

ORCID: 0000-0001-5128-8858

Irina A. Tislenkova, Cand. Sci. (Philology), Associate Professor, Department of Foreign Languages

Volgograd State Technical University

28, prospekt imeni V.I. Lenina, Volgograd, 400005, Russian Federation

tislenkova@bk.ru

ORCID: 0000-0002-7202-2773 